\title{
Raw Juice Concentration by Osmotic Membrane Distillation Process with Hydrophobic Polymeric Membranes
}

\author{
Joanna Kujawa $^{1}$ - Elena Guillen-Burrieza ${ }^{2} \cdot$ Hassan A. Arafat ${ }^{2} \cdot$ Marzanna Kurzawa $^{1}$. \\ Andrzej Wolan ${ }^{1} \cdot$ Wojciech Kujawski ${ }^{1}$
}

Received: 27 January 2015 / Accepted: 29 July 2015 / Published online: 11 August 2015

(C) The Author(s) 2015. This article is published with open access at Springerlink.com

\begin{abstract}
Hydrophobic polymeric membranes (PP, PTFE, and PVDF) were efficiently applied in juice concentration by osmotic membrane distillation process at room temperature. The properties of applied membranes were characterized by the value of static contact angle, hysteresis of contact angle, surface free energy, roughness, mean flow pore size, maximum pore size or bubble point, and the pore size distribution before and after their utilization in osmotic membrane distillation (OMD). Furthermore, the mechanical strength of the membranes was evaluated using the Mullen burst technique and characterization of fouling behavior was done. The impact of stripping solutions, characterized by different water activities $\left(\mathrm{NaCl}\right.$ and $\left.\mathrm{CaCl}_{2}\right)$, type of membrane materials, and membrane morphology, on the transport properties in a dehydration process was evaluated. Apple and beet juices with a high level of antioxidants were chosen. The quality of juices has been assessed by determination of total polyphenols and antioxidant activity. In the dehydration process, the most efficient were $0.45-\mu \mathrm{m}$ PTFE and $0.45-\mu \mathrm{m}$ PVDF membranes (24\% improvement). No loss of polyphenol content or reduction of antioxidant activity was observed after the juice dehydration.
\end{abstract}

Wojciech Kujawski

kujawski@chem.umk.pl

Faculty of Chemistry, Nicolaus Copernicus University in Torun, 7 Gagarina St., 87-100 Toruń, Poland

2 Institute Center for Water and Environment (iWater), Department of Chemical and Environmental Engineering, Masdar Institute of Science and Technology, P.O. Box 54224, Abu Dhabi, United Arab Emirates
Keywords Osmotic membrane distillation · Polymeric membranes · Juice concentration · Antioxidant activity · Total phenolic content

$\begin{array}{ll}\text { Abbreviations } \\ { }^{\circ} \text { Brix } & \text { Sugar content of an aqueous solution } \\ \text { AFM } & \text { Atomic force microscopy } \\ a_{\mathrm{w}} & \text { Water activity } \\ \text { CA } & \text { Apparent contact angle } \\ \text { CAE } & \text { Caffeic acid equivalent } \\ \text { BP } & \text { Maximum pore size or bubble point } \\ \text { ED } & \text { Electrodialysis } \\ \text { HCA } & \text { Contact angle hysteresis } \\ \text { MD } & \text { Membrane distillation } \\ \text { MF } & \text { Microfiltration } \\ \text { MPD } & \text { Mean pore distribution } \\ \text { MPS } & \text { Mean flow pore size } \\ \text { NF } & \text { Nanofiltration } \\ \text { OMD } & \text { Osmotic membrane distillation } \\ \text { PP } & \text { Polypropylene } \\ \text { PSD } & \text { Pore size distribution } \\ \text { PTFE } & \text { Polytetrafluoroethylene } \\ \text { PV } & \text { Pervaporation } \\ \text { PVDF } & \text { Polyvinylidenedifluoride } \\ \text { RMS } & \text { Root mean square (nm) } \\ \text { RO } & \text { Reverse osmosis } \\ \text { SEM } & \text { Scanning electron microscopy } \\ \text { SFE } & \text { Surface free energy (N m }{ }^{-1} \text { ) } \\ \text { TEAC } & \text { Trolox equivalent antioxidant capacity } \\ \text { TPC } & \text { Total phenolic content } \\ \text { TSS } & \text { Total suspended solids } \\ \text { UF } & \text { Ultrafiltration } \\ & \end{array}$




\section{Introduction}

Membrane separation suited a significant process in the food industry for the fractionation and concentration, as well as purification, of juices and beverages additionally for wastewater treatment. The benefits of these processes, e.g., lowtemperature conditions, no need for special chemicals, possibility of automation, and simple operation, make membrane separation a great substitute to traditional methods for treatment of liquid food (e.g., thermal pasteurization, highpressure homogenization, UV light sterilization) (Barbe et al. 1998; El-Abbassi et al. 2013; van Reis and Zydney 2007; Warczok et al. 2007a; Warczok et al. 2007b; Kujawski et al. 2013). As far as this, in the food industry, only pressuredriven processes are extensively used. However, their features restrained their utilization to diluted-solution treatment only. As a consequence, membrane processes have to be linked with traditional thermal treatments, resulting in aggravation of aroma, color, and taste of the final product. As a result, outcome a method to process concentrated juices is a difficult task (Warczok et al. 2004; Warczok et al. 2007a; Warczok et al. 2007b; Kujawski et al. 2013).

Membrane filtration methods like reverse osmosis (RO), nanofiltration (NF), ultrafiltration (UF), microfiltration (MF), membrane distillation (MD), osmotic membrane distillation (OMD), pervaporation (PV), and, to a lesser extent, electrodialysis (ED) have been commonly used in the bioprocess and food industry (Daufin et al. 2001; Ghosh 2002; van Reis and Zydney 2007; Li and Chen 2010; Claudio et al. 2009; Onsekizoglu et al. 2010). Examples of typical food processes include a combination of concentration of whey and milk as well as fractionation of milk in the dairy industry; production of soy protein concentrates and isolates; recovery of starches; clarification of juice, vinegar, and wine in the beverage industry; demineralization/decolorization/clarification of sugars and sweeteners; and applications in vegetable oil processes (Daufin et al. 2001; Ghosh 2002; van Reis and Zydney 2007; Li and Chen 2010; Claudio et al. 2009). MD and OMD have been applied for juice concentration and capsulation of aroma compounds, whereas PV has been utilized for the creation of low-alcohol beer (Babu et al. 2006; Bahçeci 2012; Barbe et al. 1998; Carlsen et al. 2010; Cassano et al. 2011; van Reis and Zydney 2007; Warczok et al. 2004; Kujawski et al. 2013). Additionally, various applications of the membranes are related to the water treatment and recycling within food process plants (Daufin et al. 2001).

OMD is a separation process in which a liquid mixture containing a volatile component is in contact with a microporous, non-wettable membrane (e.g., PVDF, PTFE, and PP) (Lalia et al. 2013; Warczok et al. 2004; Warczok et al. 2007a; Kujawski et al. 2013). During the process, both sides of the porous membrane are in contact with two aqueous solutions characterized by different water activities, e.g., a sugar solution and a stripping solution. These differences in water activity are directly related to the driving force (Warczok et al. 2004; Warczok et al. 2007a; Jiao et al. 2004; Koroknai et al. 2008; Zambra et al. 2015). As a stripping solution, organic solvents (e.g., polyglycerol and glycerol) or inorganic salts (e.g., $\mathrm{CaCl}_{2}, \mathrm{NaCl}, \mathrm{MgCl}_{2}$, and $\mathrm{MgSO}_{4}$ ) can be applied (Babu et al. 2006; Warczok et al. 2007a). The appropriate choice of the stripping solution is essential for the process effectiveness; bigger differences with water activity create a higher driving force of the OMD process.

It is interesting to focus on the OMD process improvement that is near commercialization for the concentration of beverages and other liquid foodstuff. Moreover, OMD is evaluated in terms of the concentration of aqueous solutions of thermally labile pharmaceutical products (Kolniak-Ostek et al. 2013; ElAbbassi et al. 2013).

Its principal benefit lies in its ability to concentrate solutes to very high levels at low pressure and temperature, with minimal mechanical or thermal damage or loss of the solutes. Low-alcohol-content beverages have been made in this manner with negligible losses of volatile flavor and fragrance components. Osmotic distillation promises to become an attractive follow-up or substitute to other thermal or low-temperature separation techniques such as reverse osmosis, ultrafiltration, vacuum freeze-drying, and membrane techniquepervaporation.

To the best of our knowledge, there is no report in the scientific literature concerning the application of the OMD process to the apple and beet juice concentration with additional membrane and quality juice characterization. For this reason, we decided to fill this gap. In the scientific literature, there are articles focused on the OMD process. However, these works present only the impact of experimental conditions (temperature, type of stripping solution, and type of the membrane) on the OMD efficiency process. Simultaneously, these articles do not pay attention on the quality of the products, but this is crucial from the application point of view. For instance, the comparison of the values of water fluxes for the experiments performed at different temperatures and in the isothermal conditions was presented (Rodrigues et al. 2004). In the concentration process of a model aqueous solution ( $6 \mathrm{wt} \%$ of sucrose and $1.5 \mathrm{wt} \%$ of ascorbic acid) using $\mathrm{CaCl}_{2}$ $4.0 \mathrm{~mol} \mathrm{~L}^{-1}$ as a stripping solution, an increase of about $61 \%$ in the average water flux value compared to isothermal operation was confirmed when the temperature of the stripping solution was decreased from 30 to $20^{\circ} \mathrm{C}$ (Rodrigues et al. 2004). As another example (Bélafi-Bakó and Koroknai 2006), increases in the feed temperature of $10-20{ }^{\circ} \mathrm{C}$ resulted in increments of 26-168\% in flux for pure water and two sucrose solutions (20 and $45 \mathrm{wt} \%$ ), when $\mathrm{CaCl}_{2}\left(3.5\right.$ and $\left.6.0 \mathrm{~mol} \mathrm{~L}^{-1}\right)$ at $25{ }^{\circ} \mathrm{C}$ was used as the stripping solution. Additionally, experimental data showing a higher permeate flux for OMD in the case of real juices are also presented (Bélafi-Bakó and 
Koroknai 2006; Nagaraj et al. 2006; Hongvaleerat et al. 2008). For a given activity and temperature difference, the driving force in the OMD process is actually bigger than the sum of the individual values related to osmotic dehydration and MD alone, so the link leads to a synergistic effect (Bélafi-Bakó and Koroknai 2006; Courel et al. 2000). On the other hand, articles which focused on the quality of the juices do not discuss the influence of the experimental process conditions, e.g., type of the membrane, temperature, or types of stripping solutions. The recent studies on OMD for juice concentration highlight the high quality of the achieved final product, linked with low capital investment and low energy consumption (Celere and Gostoli 2004). An integrated juice concentration process with OMD as the final filtration step preceded by ultrafiltration and reverse osmosis was presented (Jiao et al. 2004; Cassano et al. 2003). The final product was characterized by much better quality than the product acquired in a traditional way of thermal processes. Colors as well as aroma were alike to fresh juice; additionally, the total antioxidant activity was sustained. Very high juice concentration (from 20 up to 66 total suspended solids-TSS/100 g) obtained during the OMD was an additional improvement of the presented process (Cassano et al. 2003). Furthermore, a comparison of the OMD process with MD of orange juice was presented (Alves and Coelhoso 2006). It was stated that over $50 \%$ diminution of water flux in the MD process was observed comparing to the OMD one. It was related to the thermal polarization effects during the MD process.

The presented article focused on the application of osmotic membrane distillation with hydrophobic polymeric membranes made from PTFE, PVDF, and PP characterized by different pore sizes to the concentration process of apple and beet juices. Additionally, in the current work, a comprehensive characterization of the utilized membranes before and after the OMD process was done to identify the best membranes. The physicochemical characterization of the membranes was done as well as the possibility of the fouling creation was checked. Furthermore, the impact of the OMD dehydration process on the selected quality parameters of the resulting concentrated juice (e.g., an antioxidant activityTEAC - and total phenolic content-TPC) was obtained and discussed.

\section{Materials and Methods}

\section{Membranes}

In this study, four types of commercially available polymeric membranes (Table 1) were applied for apple and beet juice concentration using the OMD process. The used membranes were characterized by different pore sizes $(0.10,0.20$, and $0.45 \mu \mathrm{m}$ ) as well as were made of different materials (PTFE,
PVDF, and PP). Membranes made of these materials were chosen according to their hydrophobic character, required in the OMD process. The membrane active area was equal to $1.20 \times 10^{-3} \mathrm{~m}^{2}$.

\section{Membrane Characterization}

The presented methods and analysis were used in order to perform extensive material characterization of the membranes as well as to assess the impact of different parameters (e.g., different driving forces, type of membranes, type of feed solution) on the transport properties in the OMD process. The following parameters were evaluated: static contact angle (CA), hysteresis of contact angle (HCA), surface free energy (SFE), roughness, mean flow pore size (MPS), maximum pore size or bubble point (BP), and the pore size distribution (PSD) in order to characterize the physiochemical properties of the membrane surface. Furthermore, the mechanical strength of the membranes was evaluated by the Mullen burst technique. Additionally, a characterization of the fouling behavior was done.

For the CA and HCA measurements, a 5- $\mu$ l drop of water was placed on the membrane surface. The apparent static contact angle values and HCA were determined by a software for microscope image processing (Image J, NIH-freeware version), with an accuracy of $\pm 2^{\circ}$. In the case of SFE calculation, the Owens-Wendt method was used. In order to establish surface free energy, contact angle values for two solvents of different polarity and surface tension, i.e., water and glycerol, were measured. The procedure of SFE determination by the Owens-Wendt method for membrane samples was described in detail in our previous work (Kujawa et al. 2014).

Additionally, scanning electron microscopy (SEM) and atomic force microscopy (AFM) techniques were applied for more detailed characterization of the utilized samples (Alloisio et al. 2004). SEM and AFM were used to examine the morphology and roughness of the membrane surfaces, respectively. Images were acquired using a tapping mode in air for both pristine and used membranes in the OMD process. The scan size was equal to $1 \times 1 \mu \mathrm{m}$ for all examined membranes. From the scanned images, the root mean square (RMS) roughness values were obtained. SEM analysis was performed using a Quanta 3D FEG equipment. Surface analysis was carried out using AFM equipment with a NanoScopeMultiMode SPM System and NanoScopeIIIaiQuadrex controller (Veeco, Digital Instrument, UK).

The MPS, maximum pore size or BP, and the PSD were measured using a capillary flow porometer (CFP, Porous Materials Inc., Ithaca, USA). The membrane's total porosity was calculated experimentally using a low-surface-tension liquid (Silwick ${ }^{\circledR}$, provided by PMI, Ithaca, NY, USA) of known density. Finally, the mechanical strength of the membranes 
Table 1 Characteristics of applied commercial membranes - parameters provided by manufacturers

\begin{tabular}{lllll}
\hline Membrane material & Pore diameter $(\mu \mathrm{m})$ & Thickness $(\mu \mathrm{m})$ & Porosity $(\%)$ & Manufacturer \\
\hline PP (polypropylene) & 0.10 & 170 & 75 & Celgard (USA) \\
PTFE (polytetrafluoroethylene) & 0.20 & 65 & 62 & Sartorius Stedim (Germany) \\
PVDF (polyvinylidenedifluoride) & 0.45 & 80 & 80 & Durapore Merck (Germany) \\
\hline
\end{tabular}

was assessed by using the Mullen burst technique which measures the pressure required to break the membrane. Details about these characterization techniques can be found in Lalia et al. (2013). According to these analyses, it was possible to evaluate the impact of the OMD process on the membrane morphology.

\section{Osmotic Membrane Distillation}

OMD experiments were performed using a laboratory setup, schematically depicted in Fig. 1. The OMD module consists of two compartments. The volume of each compartment is $150 \mathrm{~cm}^{3}$. The stripping solutions $\left(\mathrm{NaCl}\right.$ or $\left.\mathrm{CaCl}_{2}\right)$ and the feed juice solution (apple or beet juice) are separated by the hydrophobic flat membranes (Table 1). The raw juices were used without any additives or preservatives. Apple juice was purchased from "Marwit Sp. z o.o." (Poland) company, and beet juice from by "Piotr i Pawel" (Poland) company. $\mathrm{NaCl}$ and $\mathrm{CaCl}_{2}$ were purchased from Avantor Performance Materials Poland S.A. The stripping compartment was hermetically sealed, so the volume measured by the pipette is equal to the volume of water transported across the membrane from the juice solution to the stripping solution (Fig. 1). Both solutions were constantly stirred. All experiments were done at a constant temperature of $20^{\circ} \mathrm{C}$. The choice of room temperature aimed to show the efficiency of dewatering juices without requiring an elevated temperature. However, the following experimental conditions were varied: the duration of the experiment (from 3 to $11 \mathrm{~h}$ ), different stripping solutions (saturated $\mathrm{NaCl}-25 \% \mathrm{w} / \mathrm{w}$ - and $\mathrm{CaCl}_{2}-50 \% \mathrm{w} / \mathrm{w}$ ), and different feed solutions (apple and beet juices). Moreover, the experiments were done for all purchased membranes (Table 1). Deionized water $\left(0^{\circ} \mathrm{Brix}\right)$ and fresh juices (apple and beet) of initial concentration $\left(\sim 11^{\circ}\right.$ Brix $)$ were used as feed solutions. Juices were pre-filtrated to remove the fruit pulp before the OMD process. This procedure was required, because raw juices, containing a lot of pulp that could clog the pores of membranes, were utilized. The pre-filtration process was conducted under low pressure with application of $2-\mu \mathrm{m}$ filter papers. It was found that the pre-treatment step had no impact on the quality of the juices subsequently processed by the OMD process.
Each OMD experiment was run in batch mode using a new membrane sample, fresh feed, and stripping solution. Every single experiment was repeated three times.

\section{Analytical Methods}

In order to assess the performance of the OMD system, the following parameters were taken into account: the flux through the membrane and the juice concentration at the beginning and at the end of the process. The flux was measured by collecting and weighing the permeate in a given period of time. The initial and final concentrations of the apple and beet juices and stripping solutions $\left(\mathrm{CaCl}_{2}\right.$ and $\left.\mathrm{NaCl}\right)$ were measured by using an Abbe refractometer (PZO-RL1, Warsaw, Poland). The refractive index is linearly dependent on the concentration of salts in solution. Therefore, the water activities of $\mathrm{CaCl}_{2}$ and $\mathrm{NaCl}$ solutions could be determined from their respective refractive indexes and calibration curve relating water activity and salt concentration (Chirife and Resnik 1984; Sereno et al. 2001).

The quality of the juices was evaluated following presented methods. The TPC of both apple and beet juices was determined using the Folin-Ciocâlteu method described elsewhere (Rózek et al. 2007). The antioxidant capacity was determined as the Trolox equivalent antioxidant capacity (TEAC) assay. The 2,20-azinobis(3-ethylbenzothiazoline-6-sulfonic acid)

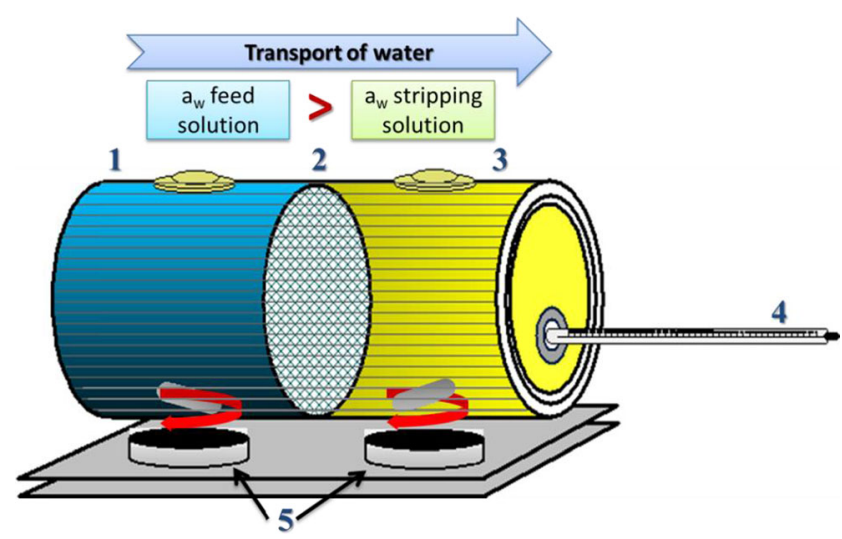

Fig. 1 Scheme of the OMD experimental setup. 1 feed solution chamber, 2 hydrophobic membrane, 3 stripping solution chamber, 4 calibrated pipette, 5 magnetic stirrers 
diammonium salt (ABTS) was chosen as a molecule determining the activity of both lipophilic and hydrophilic antioxidants. The procedure in detail was presented elsewhere (Zielinska et al. 2007). In order to evaluate the possibility of degradation of applied juices, the stripping solutions were also analyzed.

\section{Results}

\section{Surface Characterization of Commercially Available Membranes (PP, PTFE, PVDF)}

\section{Before OMD Process}

Surface properties have a great impact on the membrane performance. For this reason, wide characterization of the physicochemical properties of the surface was done.

The morphology of the applied membranes is presented in Fig. 2. Based on these SEM images, it can be seen that all membranes are characterized by different morphologies. PP and PVDF membranes possessed higher porosity and thickness. PTFE membranes with a smaller pore size were characterized by lower values of thickness $(65 \mu \mathrm{m})$ and porosity (62\%) (Table 1). The porosity and thickness for $0.45-\mu \mathrm{m}$ PTFE membranes were equal to $80 \%$ and $80 \mu \mathrm{m}$, respectively. Polypropylene (PP) membrane has a fiber-like structure as it can be observed in the cross section image (Fig. 2(I)).

PTFE membranes are expanded-film membranes made of polytetrafluoroethylene by the uniaxial or biaxial stretching process resulting in an interconnected pore structure (Kujawski et al. 2013; Warczok et al. 2007b). SEM images of the PTFE membranes shown in Fig. 2(II and III) indicated a very similar skin structure of the 0.20 - and $0.45-\mu \mathrm{m}$ membranes. However, it is possible to observe a relatively more open pore structure of the $0.45-\mu \mathrm{m}$ membrane than that of the $0.20-\mu \mathrm{m}$ membrane. These observations are consistent with the pore size distribution obtained by the capillary flow porometry technique (Fig. 3). The polyvinylidenedifluoride (PVDF) membrane was characterized by a sponge-like structure (Fig. 2(IV)). Additionally, compared to the rest of the membranes, PVDF 0.45 has a very broad PSD (ranging from 0.8 to $0.25 \mu \mathrm{m})$ and the largest $\mathrm{BP}(0.800 \pm 0.002 \mu \mathrm{m})$ that represented quite a large amount of the total pores $(\sim 3 \%)$. PTFE membranes showed both narrower PSDs (both with a span of $\sim 0.2 \mu \mathrm{m})$ and different BPs, being that of the PTFE $0.2(0.40 \mu \mathrm{m})$ almost half of the PTFE 0.45 $(0.729 \pm 0.014 \mu \mathrm{m})$. PP had the narrowest PSD and the smallest BP $(0.088 \pm 0.001 \mu \mathrm{m})$. A summary of the membrane characterization prior to the OMD process is shown in Table 2.

All investigated membranes were characterized by contact angle values higher than $90^{\circ}$, which corresponds to their hydrophobic behavior (Table 2). Membrane materials have a clear impact on the hydrophobicity. The most hydrophobic membranes were made from PTFE. However, the lowest hydrophobicity level was observed for PP membranes (i.e., CA $113^{\circ}$ ). HCA values were strongly associated with membrane materials and pore size of the tested membranes. It can be seen (Table 2) that for a more smooth material (PVDF), characterized by a lower value of RMS $(50 \pm 2 \mathrm{~nm})$, the contact angle hysteresis is lower $\left(28^{\circ} \pm 1^{\circ}\right)$. SFE values were in the range of $38.0 \times 10^{-3}$ to $51.2 \times 10^{-3} \mathrm{~N} \mathrm{~m}^{-1}$. This parameter (SFE) is directly related to the hydrophobicity. For that reason, the lowest value of SFE was noticed for the membrane characterized by the highest CA value (PTFE 0.45). Surface free energy for the examined membranes depends on the membrane materials as well as on the pore size. The highest value of SFE was observed for the PP membrane (i.e., RMS $125 \pm 3 \mathrm{~nm}$ ) and was associated with the morphology of the membrane, a fiber-like structure (Fig. 2.I). On the other hand, the lowest SFE value was determined for the $0.45-\mu \mathrm{m}$ PTFE membrane (i.e., RMS $65 \pm 2 \mathrm{~nm}$ ). Roughness of the membrane surface (RMS) was associated with the HCA value, and for more rough samples, a higher value of contact angle hysteresis was observed (Table 2). Furthermore, it should be highlighted that the roughness correlates well with the membrane materials. According to that, the utilized membranes should be classified into three groups and considered as PP, PTFE, and PVDF membranes. Based on that assumption, it can be stated that for more rough samples, higher values of SFE are observed. The RMS values are well correlated with $\mathrm{CA}$ and SFE values.

\section{After the OMD Process}

In order to investigate the impact of the OMD process on the membrane properties, an extensive characterization of the membrane was done. During the OMD, different membranes (PP $0.10 \mu \mathrm{m}$, PTFE 0.2 and $0.45 \mu \mathrm{m}$, PVDF $0.45 \mu \mathrm{m}$ ) and stripping solutions $\left(\mathrm{NaCl}\right.$ and $\left.\mathrm{CaCl}_{2}\right)$ as well as feed solutions (water, beet and apple juices) were applied. After the OMD process, differences in physicochemical properties of the membranes were observed.

The hydrophobicity level of the polymeric membranes was changed. It was associated with the organic layer created on the membrane surface remaining after cleaning the membranes. Depending on the experimental conditions and applied juices, it was possible to notice a layer on the whole surface or on only a part of the membrane (Fig.4).

The obtained values of the contact angle for the membranes after the OMD process were lower than those for native samples (Table 2). The differences between CA values before and after the OMD processes were equal to about $8^{\circ}-13^{\circ}$. The largest difference was observed for the $0.45-\mu \mathrm{m}$ PTFE membrane from $133^{\circ} \pm 1^{\circ}$ to $120^{\circ} \pm 1^{\circ}$, however the smallest for PVDF and PP membranes from $120^{\circ} \pm 1^{\circ}$ to $112^{\circ} \pm 1^{\circ}$ and 
Fig. 2 SEM images of used polymeric membranes: $\mathrm{PP}$ $0.10 \mu \mathrm{m}(I)$, PTFE $0.20 \mu \mathrm{m}(I I)$ and $0.45 \mu \mathrm{m}$ (III), and PVDF (IV). $O$ obverse and $R$ reverse sides of the membranes. Magnitude 200×, 2000×, and $10000 \times$
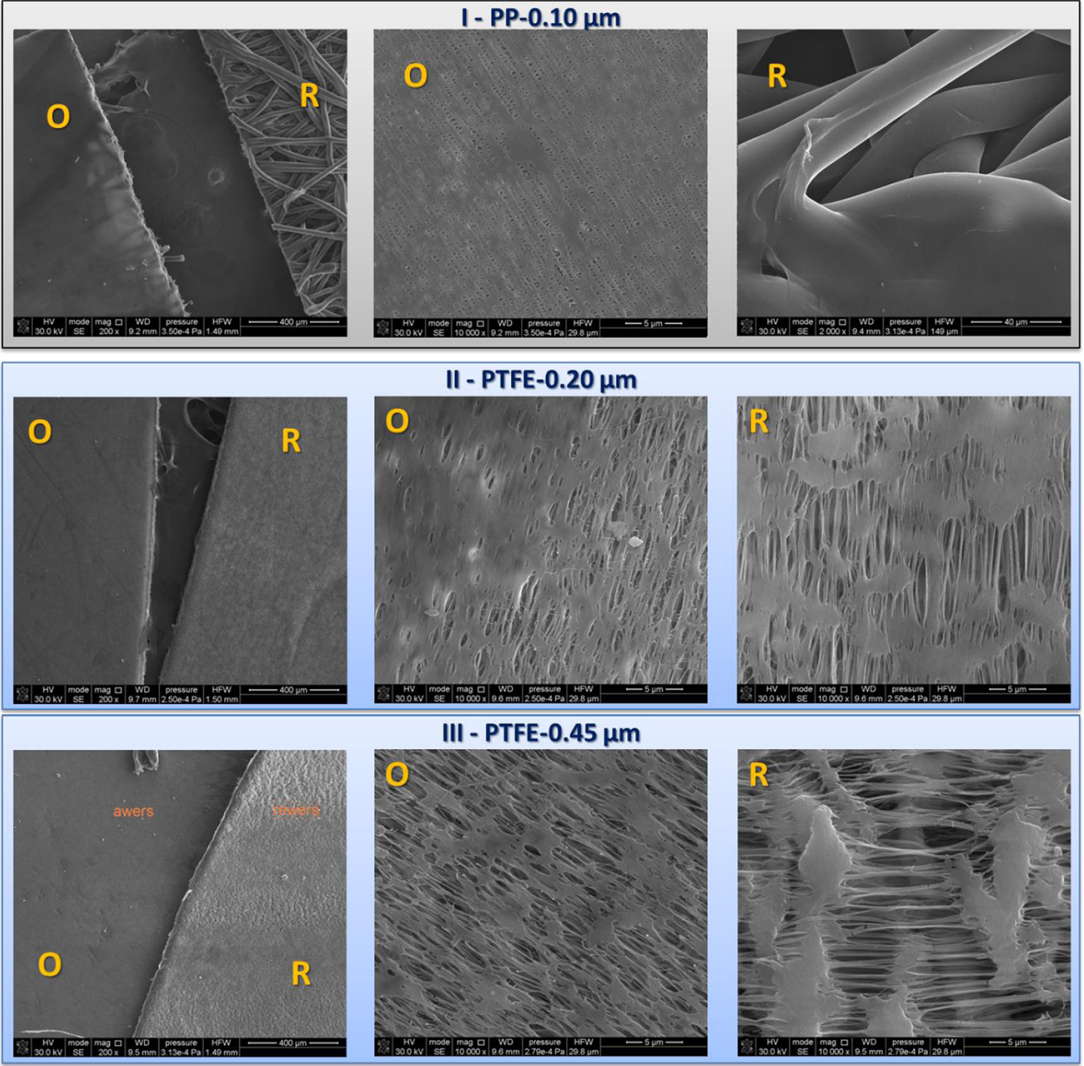

III - PTFE- $0.45 \mu \mathrm{m}$
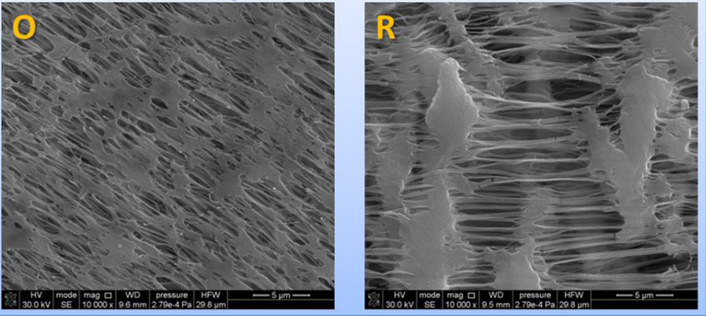

IV - PVDF-0.45 $\mu \mathrm{m}$
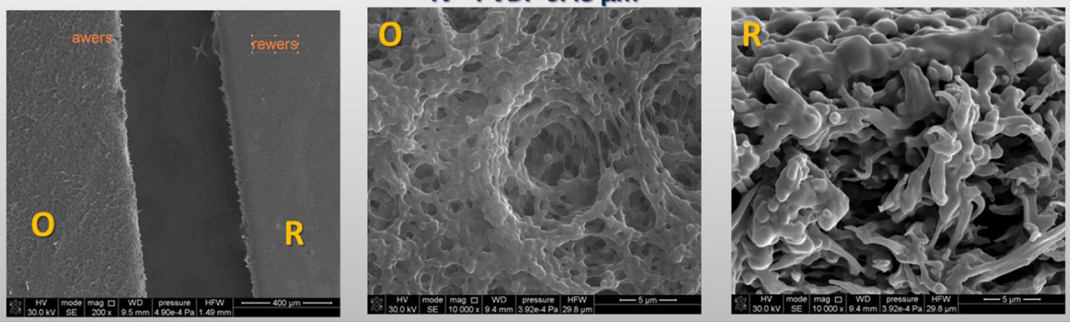

HCA and were more rough (RMS) comparing with the unused from $113^{\circ} \pm 1^{\circ}$ to $105^{\circ} \pm 1^{\circ}$, respectively (Table 2). Membranes utilized in the OMD process demonstrated a higher value of
Fig. 3 Pore size distribution (PSD) of the studied membranes

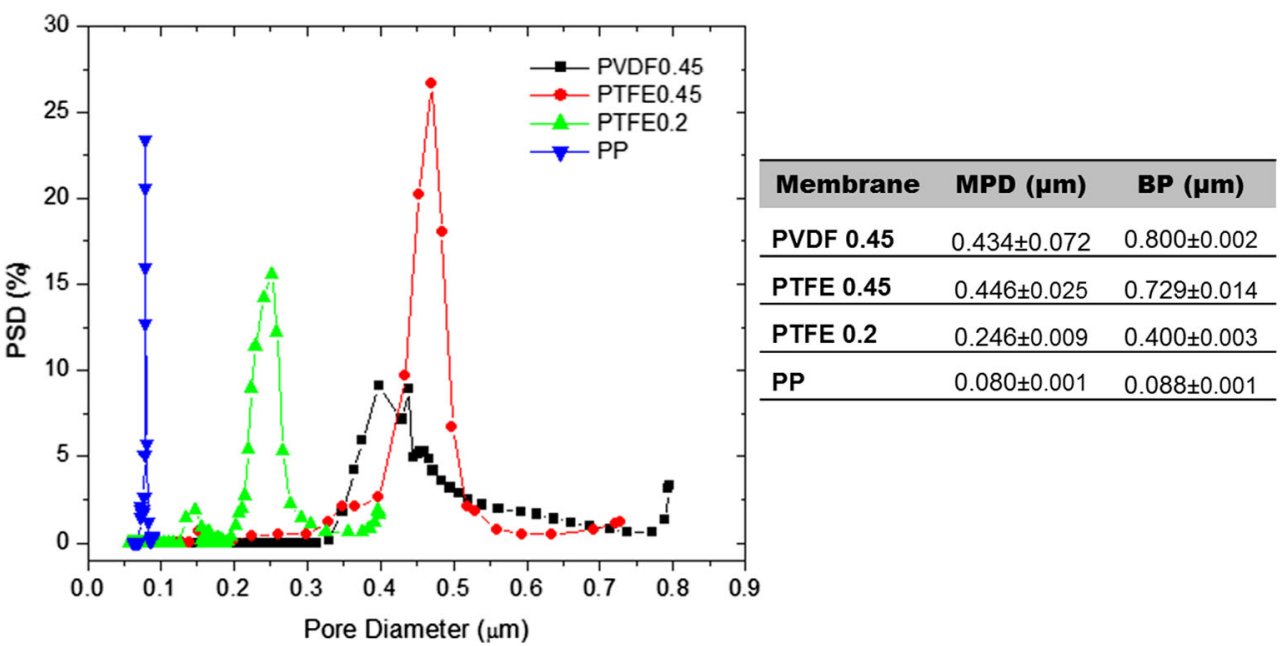


Table 2 Surface properties of membranes before and after application in the OMD process (feed solutions: apple and beet juices; stripping solution: $\mathrm{CaCl}_{2}$ )

\begin{tabular}{|c|c|c|c|c|}
\hline Membrane & $\mathrm{CA}\left({ }^{\circ}\right)$ & $\mathrm{HCA}\left({ }^{\circ}\right)$ & $\operatorname{SFE}\left(10^{-3} \mathrm{~N} \mathrm{~m}^{-1}\right)$ & RMS (nm) \\
\hline \multicolumn{5}{|l|}{ Pristine membranes } \\
\hline PP $0.10 \mu \mathrm{m}$ & $113 \pm 1$ & $36 \pm 1$ & $51.2 \pm 0.4$ & $125 \pm 3$ \\
\hline PTFE $0.20 \mu \mathrm{m}$ & $121 \pm 1$ & $34 \pm 1$ & $42.3 \pm 0.3$ & $70 \pm 2$ \\
\hline PTFE $0.45 \mu \mathrm{m}$ & $133 \pm 1$ & $33 \pm 1$ & $38.0 \pm 0.3$ & $65 \pm 2$ \\
\hline PVDF $0.45 \mu \mathrm{m}$ & $120 \pm 1$ & $28 \pm 1$ & $41.6 \pm 0.3$ & $50 \pm 2$ \\
\hline \multicolumn{5}{|c|}{ Membrane after the OMD process } \\
\hline PP $0.10 \mu \mathrm{m}$ & $105 \pm 1$ & $54 \pm 1$ & $59.3 \pm 0.4$ & $150 \pm 4$ \\
\hline PTFE $0.20 \mu \mathrm{m}$ & $111 \pm 1$ & $52 \pm 1$ & $57.9 \pm 0.4$ & $120 \pm 3$ \\
\hline PTFE $0.45 \mu \mathrm{m}$ & $120 \pm 1$ & $40 \pm 1$ & $43.7 \pm 0.3$ & $103 \pm 3$ \\
\hline PVDF $0.45 \mu \mathrm{m}$ & $112 \pm 1$ & $50 \pm 1$ & $55.0 \pm 0.4$ & $60 \pm 2$ \\
\hline
\end{tabular}

organic residues from the juices on the membrane surfaces (Fig. 4). Taking into consideration the SFE, it can be seen that after the membrane application in the OMD process, these values slightly increased (Table 2). This fact can be associated with the small changes in the membrane resistance and mechanical strength after the OMD process, especially in the case of the $0.45-\mu \mathrm{m}$ PTFE membrane. For this sample, changes with mechanical strength were the most visible.

Porosity and mechanical strength (Mullen burst test) results for the membranes before and after the OMD concentration process have been represented in Fig. 5.

Regarding the porosity values, PTFE membranes showed higher values (60.3 and $51 \%$ for PTFE 0.45 and PTFE 0.2 ,
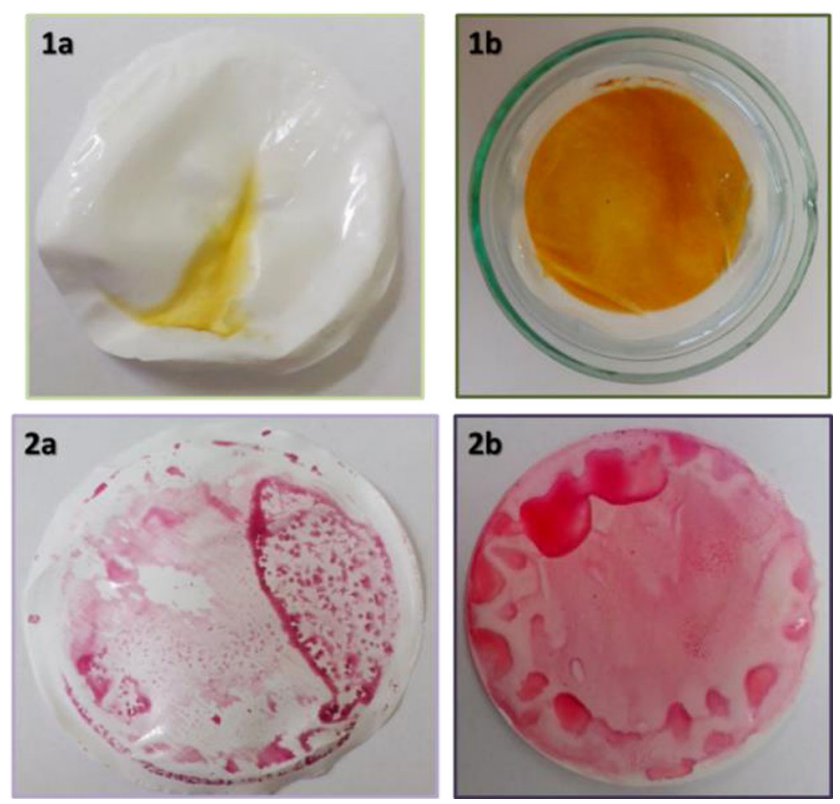

Fig. 4 The 0.45- $\mu \mathrm{m}$ PTFE membrane after the OMD processes in the following systems: $1 a \mathrm{NaCl}$ /apple juice, $1 b \mathrm{CaCl}_{2}$ /apple juice, $2 a \mathrm{NaCl} /$ beet juice, $2 b \mathrm{CaCl}_{2} /$ beet juice

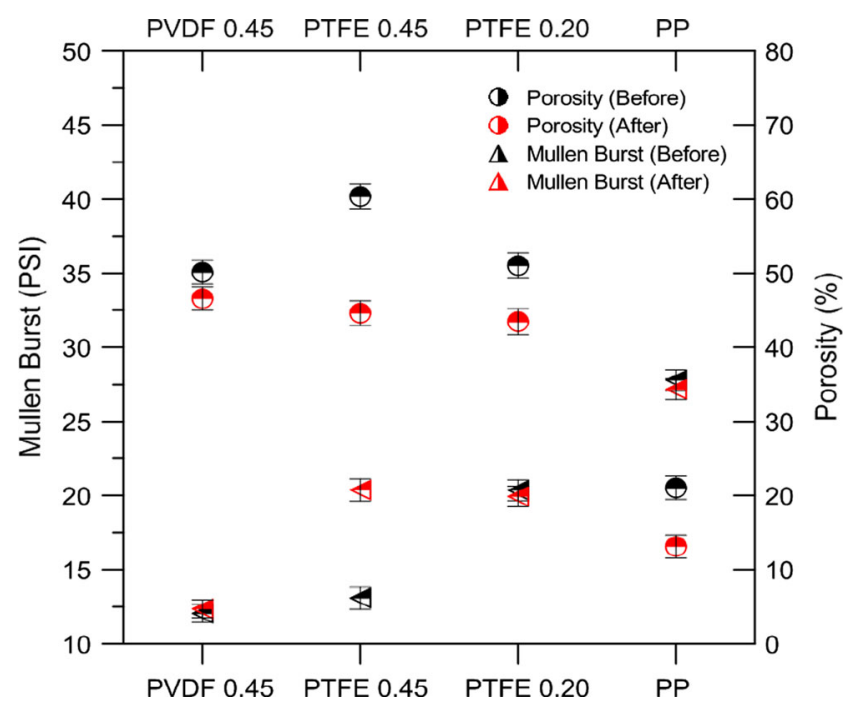

Fig. 5 Porosity and mechanical strength (Mullen burst test) results for the studied membranes before and after their application in the OMD process (feed solutions: apple and beet juices; stripping solution: $\mathrm{CaCl}_{2}$ )

respectively) followed by PVDF 0.45 (50\%). PTFE membranes due to their open structure show high porosities in general; as for the PVDF 0.45 , its relatively big and broad PSD is also reflected in big porosity values. PP showed a remarkably lower porosity ( $21 \%)$, most probably due to its relatively smaller PSD. Also, as revealed by the SEM images, the PP membrane showed a much less porous surface wherever the imprints of its particular backer material were located. However, it was related to the fact that the PP membrane possesses a support on the backer side (Fig. 2(I)). After the OMD process, a general reduction of the porosity in the tested membranes was observed (Fig. 5). The PVDF 0.45 seemed to be the least affected ( $7 \%$ reduction) while the PP showed the biggest decrease $(37 \%)$. The other two membranes, PTFE 0.45 and PTFE 0.2 , showed a porosity reduction of 26 and $15 \%$, respectively. Most probably, the bigger thickness and more open structure of the PVDF membrane result from a sponge-like structure, when compared to its counterparts. This could prevent the porosity reduction after the OMD process. Mullen burst tests did not reveal an important influence of the fouled condition in the mechanical strength of the studied membranes (Fig. 5). Amongst the studied membranes, PP showed the highest burst pressure probably due to its support (27.8 PSI). In general, all the membranes had similar or slightly smaller burst pressure post OMD application with the only exception of the PTFE 45 which showed a higher value, and that might have been due to a comparatively greater fouling layer accumulated in that particular sample. The fouled membranes were also studied under SEM (Fig. 6).

The PVDF membrane has a sponge-like structure with a very high surface porosity consisting of big pores $(>1 \mu \mathrm{m})$ randomly distributed on the surface (Fig. 3) combined with the less hydrophobic nature of the PVDF comparing with 
Fig. 6 SEM pictures of the studied membranes after their application in the OMD process. a PVDF 0.45 membrane (surface); b PVDF 0.45 membrane (cross section); c, d PTFE 0.45 membrane (surface); e, f PTFE 0.2 membrane (surface); $\mathbf{g}, \mathbf{h}$ PP membrane (surface). OMD conditions: feed solution: apple juice; stripping solution: $\mathrm{CaCl}_{2}$
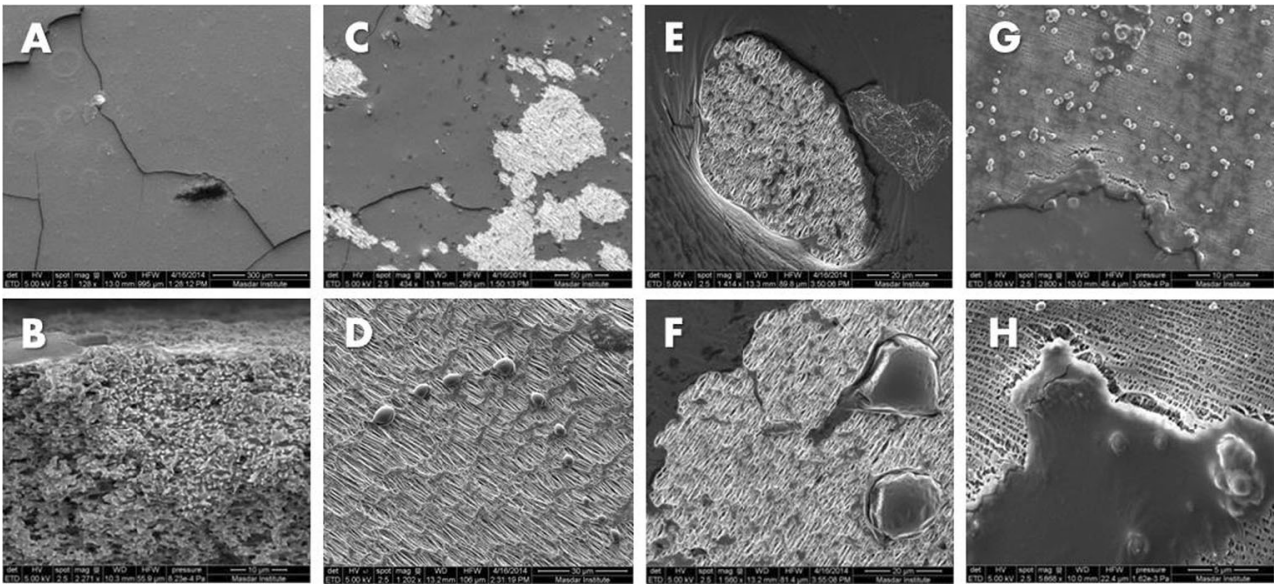

PTFE that makes this membrane prone to fouling. The SEM images showed an almost continuous fouling layer on top of the PVDF membrane. Moreover, the cross section images (Fig. 6b) revealed the presence of scattered internal deposits. However, the depth $(<10 \mu \mathrm{m})$ and occurrence of the internal deposits when compared to the thickness of the membrane $(123 \mu \mathrm{m}$ - Table 1) did not have a great impact on its porosity as shown in Fig. 5. In the case of the PTFE membranes, SEM images showed randomly distributed clean membrane patches that remained uncovered by the fouling layer (Fig. 6c, e) with clear boundaries between the fouling layer and the clean membrane. The images also show clearly the identified nucleation sites where the fouling process started (i.e., the nodes in between the PTFE fibers) as shown in Fig. 6d. Those nucleation sites would most likely reduce the hydrophobicity of the active surface (Table 2) of the membrane and promote the spreading of the fouling layer. Finally, the PP membrane images showed a quite thick fouling layer similar to that found on the PVDF one, but in this case, some clean membrane patches remain clean; however, the separation between the clean membrane and the fouling layer was less clear (Fig. 6g) than in the PTFE membranes. There was also a much bigger population of nucleation sites (Fig. 6g) but apparently randomly distributed. The images revealed also apparent cracks in the membrane/fouling layer next to the fouling patches. However, the Mullen burst test (Fig. 5) did not reflect the presence of the cracks (a lower burst pressure for the fouled condition would be expected from the presence of the cracks) most probably because of the masking effect of the backer material.

\section{Transport Properties}

\section{OMD with Pure Water}

During the OMD experiments, two osmotic agents $(\mathrm{NaCl}$ and $\left.\mathrm{CaCl}_{2}\right)$ with different water activities $(\sim 0.80$ for $\mathrm{NaCl}$ and $\sim 0.20$ for $\mathrm{CaCl}_{2}$ ) were employed. For this reason, it was possible to evaluate the impact of the driving force on the transport properties of the investigated membranes.

The characteristic time evolution of water flux in OMD for the PP membrane is presented in Fig. 7. The experiment was done for pure water as a feed and $\mathrm{CaCl}_{2}$ solution as a stripping solution. It can be noticed that at the beginning of the OMD experiment, the water permeate flux rapidly decreased. A similar initial behavior of the system was caused by the geometry of the experimental cell and by the way of filling of the compartments of the cell. At the beginning of each experiment, the membrane sample marginally changed its geometry causing the rapid removal of the excess solution from the stripping compartment. Such behavior is always observed at the beginning of the OMD experiment (Warczok et al. 2007b; Kujawski et al. 2013).This initial part of the experiments was not taken into account. After 45-60 min of the experiment, the system achieved a pseudo-stationary state (Warczok et al. 2007b; Kujawski et al. 2013).

In Fig. 8, the results are presented for the OMD experiments with pure water as a feed and $\mathrm{NaCl}$ or $\mathrm{CaCl}_{2}$ as a stripping solution. During these experiments, membranes characterized by different pore sizes and made of different materials were used. In the case of the application of sodium chloride as a stripping solution, water permeate fluxes obtained for all investigated membranes were smaller than those for experiments with $\mathrm{CaCl}_{2}$ as a stripping solution. This observation was related to a higher driving force obtained for $\mathrm{CaCl}_{2}$ applied as a stripping solution (Babu et al. 2006; Warczok et al. 2007b; Kujawski et al. 2013). For the system with $\mathrm{NaCl}$, the driving force expressed by a difference of water activity is much smaller than in the case of the $\mathrm{CaCl}_{2}$ solution. Generally, water permeate fluxes obtained in the OMD experiment with $\mathrm{CaCl}_{2}$ as a stripping solution were 1.5 times higher than for experiments with $\mathrm{NaCl}$ (Warczok et al. 2007b; Kujawski et al. 2013). This behavior can be noticed for PVDF and both PTFE membranes. For the PP membrane, the water permeate flux increased 2.7 times. It can be correlated with the different membrane morphology of the PP membrane (fiber-like 


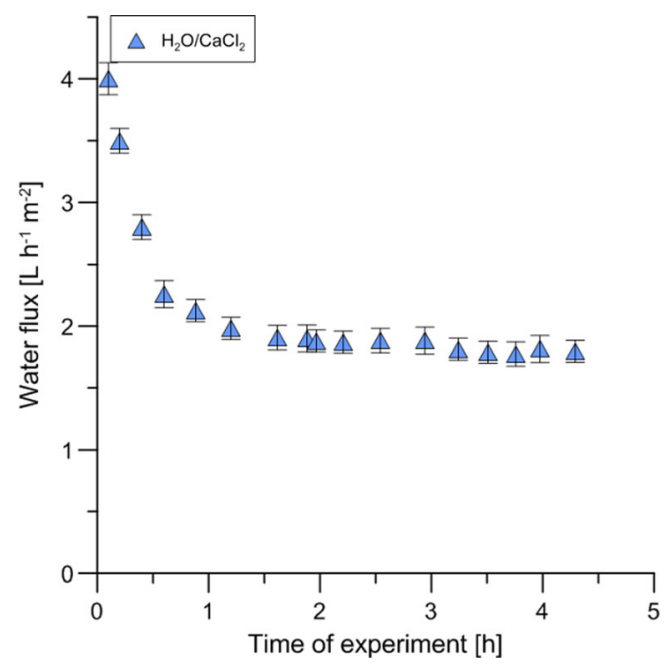

Fig. 7 Water permeate flux vs. time of experiments for the $0.1-\mu \mathrm{m}$ PP membrane. System: $\mathrm{H}_{2} \mathrm{O} / \mathrm{CaCl}_{2}$ at room temperature

structure, pore size, and thickness) in comparison with the other ones (Fig. 1). Polypropylene membranes possessed the smallest pore size (Fig. 3) and are characterized by the highest thickness (Table 1). Additionally, because of the fiber-like structure, these membranes have a small pore area (Fig. 1). Regardless of the investigated systems, the highest water permeate values were obtained for the $0.45-\mu \mathrm{m}$ PTFE membrane. This behavior can be associated with the highest porosity $(80 \%)$ and with a relatively small thickness $(80 \mu \mathrm{m})$ of the $0.45-\mu \mathrm{m}$ PTFE membranes (Table 1). The lowest water permeate flux was observed for PP membranes in both OMD experiments with different stripping solutions (Fig. 8). This fact, similar to the $0.45-\mu \mathrm{m}$ PTFE, is directly related to the morphology of the membrane (Table 1 and Fig. 2). The PP membrane was characterized by the lowest value of pore diameter $(0.10 \mu \mathrm{m})$ and by the biggest thickness $(170 \mu \mathrm{m})$. Moreover, it can be noticed that the obtained permeate fluxes for the $0.20-\mu \mathrm{m}$ PTFE and the $0.45-\mu \mathrm{m}$
PVDF are very similar. Summarizing, the following factors: morphology of the membranes and type of membrane material, have an important impact on the transport properties of the tested membranes (Table 3 and Fig. 8). Moreover, the experimental conditions of the OMD process influence on the efficiency of the water transport across the utilized membranes. The most effective membrane, characterized by the best transport properties expressed by the highest value of the permeate flux, was the $0.45-\mu \mathrm{m}$ PTFE. The diminution of transport properties was observed during the process with membranes characterized by a bigger pore size independently of the stripping solutions (Fig. 8).

\section{Application of OMD in the Concentration of Juices}

After the OMD experiments with pure water, the transport and selective properties of the hydrophobic polymeric membranes were evaluated in the OMD process with juices. Two types of juices were utilized as feed solutions - apple and beet juice.

These juices were chosen because they are valuable for the human health (Zhao et al. 2013; Al-Sheraji et al. 2013) and possess high level of antioxidants (polyphenol and flavonoids) (Le Marchand et al. 2000; Boyer and Liu 2004). For this reason, it is very important to protect these valuable ingredients against the removal or degradation during the dehydration juice process. The degradation of the antioxidants is a disadvantage of the thermal method applied for the beverage dehydration process (Altamirano et al. 1992; Jiratanan and Liu 2004). For these reasons, the OMD process performed at room temperature has an important predominance for juice dehydration.

The permeate fluxes obtained during the OMD process with the $0.45-\mu \mathrm{m}$ PTFE membranes are presented in Fig. 9. According to the obtained results, it can be seen that the type of stripping solution has an important influence on the
Fig. 8 Water flux vs. time of experiments for $0.10-\mu \mathrm{m} P$, 0.20 - $\mu \mathrm{m}$ PTFE, 0.45- $\mu \mathrm{m}$ PTFE, and $0.45-\mu \mathrm{m}$ PVDF. Systems: water/ $\mathrm{NaCl}$ (a) and water/ $\mathrm{CaCl}_{2}$ (b) at room temperature
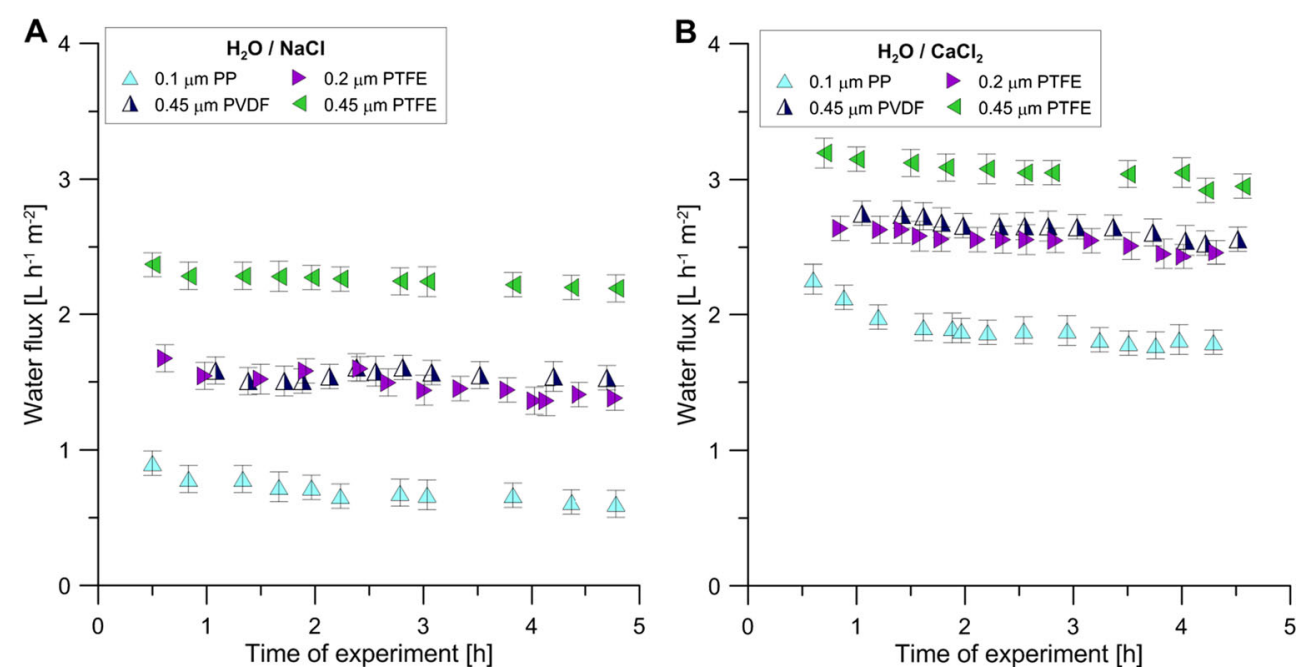


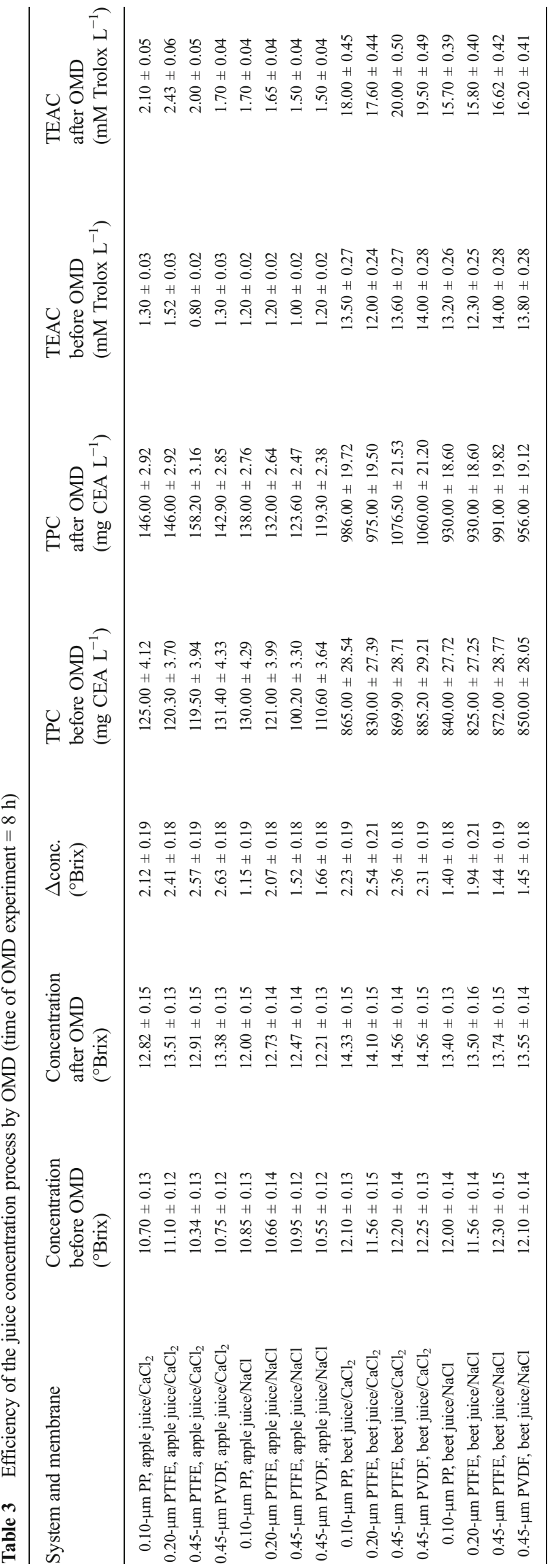

transport properties. This behavior was directly associated with the different water activities for $\mathrm{NaCl}\left(a_{\mathrm{w}}=0.8\right)$ and $\mathrm{CaCl}_{2}\left(a_{\mathrm{w}}=0.2\right)$. The presented results were consistent with results obtained for pure water as a feed (Fig. 8). On the other hand, the type of juice has no influence on the transport properties. This fact is related to the similar sugar content $\left(11.4 \pm 0.6^{\circ}\right.$ Brix $)$ and water activity of the applied juices $(0.990 \pm 0.002)$. Moreover, it can be observed that permeate fluxes decrease during the course of experiments (Fig. 9). This reduction of the permeate flux during the experiments is associated with the decrease of driving force. The decrease of the driving force is explained by diminution of salt concentration during the process due to dehydration of juice. As a result of reduction of the stripping solution, concentration is the increase of water activity for salt and thus decrease of driving force for the dehydration process. The highest reduction equal to around $30 \%$ was observed for the PVDF membrane tested with the system beet juice as a feed and $\mathrm{CaCl}_{2}$ as a stripping solution (Fig. 10). Moreover, the smallest reduction in the permeate flux was noticed for the PTFE 0.45 membrane (12\%) (Fig. 9).

Additionally, it can be seen that the type of membrane material has very little influence on the transport properties in OMD of juices (Fig. 10). Permeate fluxes for membranes with smaller pore sizes of 0.10 and $0.20 \mu \mathrm{m}$ were slightly higher than for membranes with a bigger pore size of $0.45 \mu \mathrm{m}$; however, the differences are marginal. This phenomenon was also described in the literature (Hwang et al. 2008). For membranes with a smaller pore size, the permeate fluxes were marginally higher which can show lower surface fouling and pore blocking than in the case of the membranes with a higher pore size (Fig. 6). The suspended particles, bigger than $0.2 \mu \mathrm{m}$, can block pores of $0.45-\mu \mathrm{m}$ membranes leading to flux decrease. In the literature, it was highlighted that membranes with a bigger pore size are more vulnerable to fouling (Hwang et al. 2008; Kujawski et al. 2013). Alike results were obtained by Kujawski et al. (2013). The authors investigated PTFE membranes with different pore sizes of $0.20,0.45$, and $1.20 \mu \mathrm{m}$. These membranes were applied in the OMD process with red grape juice (Kujawski et al. 2013).

It was found that after $8 \mathrm{~h}$ of experiment, the concentration of juices increased by about $1.44-2.63{ }^{\circ}$ Brix depending on the conditions of experiments and the applied membrane (Table 3). The highest improvement of juice concentration was observed for the system apple juice $/ \mathrm{CaCl}_{2}$ and the $0.45-\mu \mathrm{m}$ PVDF membrane ( $20 \%$ higher concentration after $8 \mathrm{~h}$ of experiment). A strong impact of the type of stripping solution on the final concentration of juices was observed (Table 3). In general, lower final juice concentration values were found for $\mathrm{NaCl}$ as a stripping solution (Table 3). This behavior was related to the lower driving force for the $\mathrm{NaCl}$ solution. 
Fig. 9 Permeate flux vs. time of experiments for the $0.45-\mu \mathrm{m}$ PTFE membranes. Systems: apple juice/ $\mathrm{NaCl}$ and apple juice/ $\mathrm{CaCl}_{2}($ a) and beet juice/ $\mathrm{NaCl}$ and beet juice $/ \mathrm{CaCl}_{2}$ (b) at room temperature
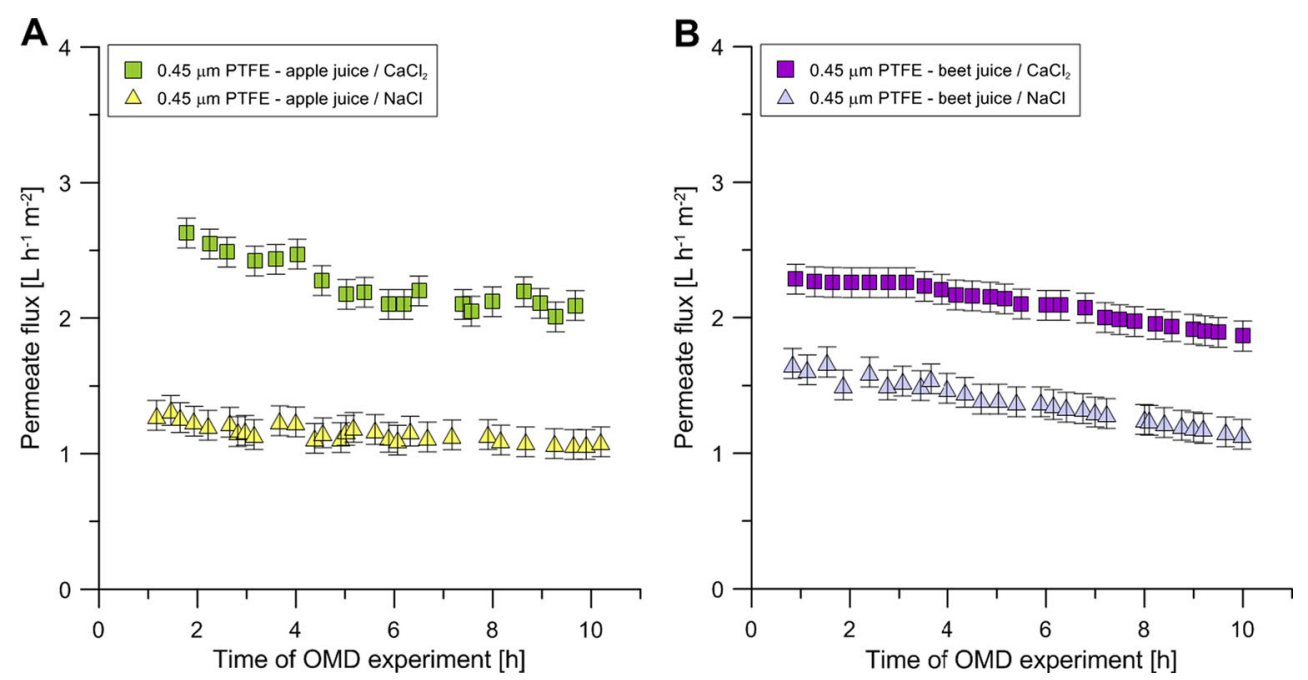
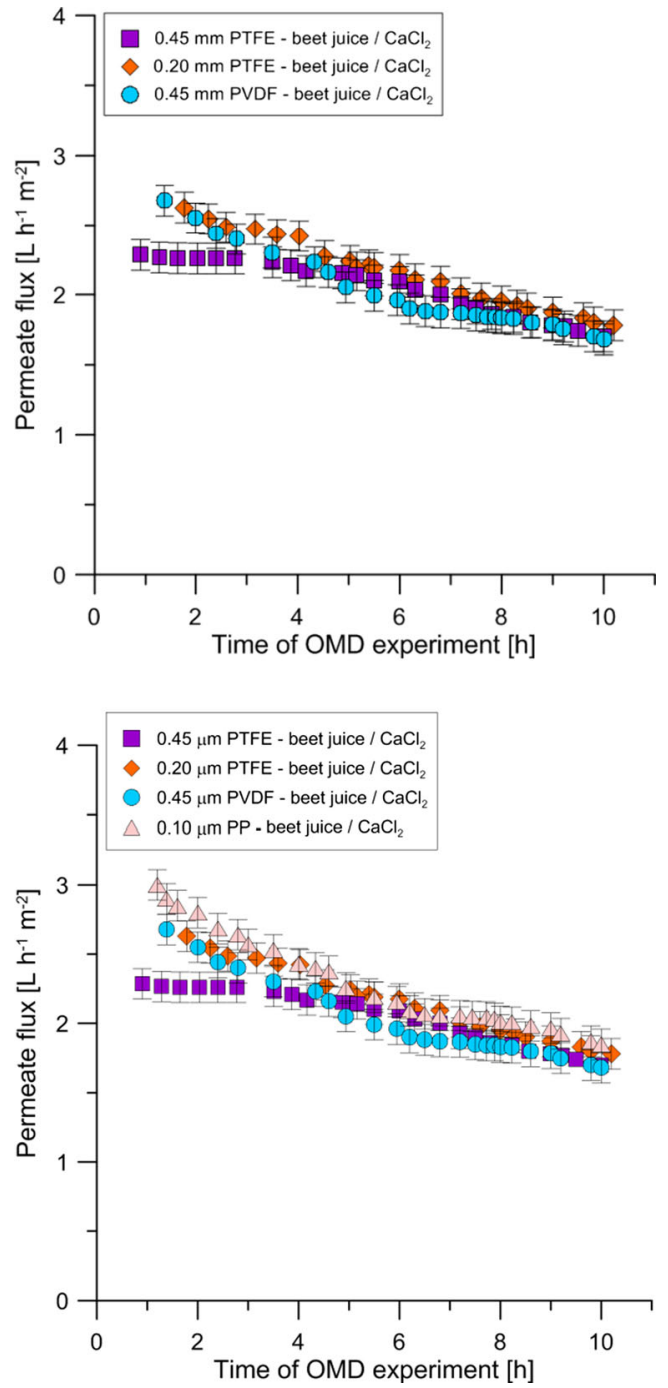

Fig. 10 Permeate flux vs. time of experiments for the 0.20 - and $0.45-\mu \mathrm{m}$ PTFE and $0.45-\mu \mathrm{m}$ PVDF membranes. System: beet juice/ $\mathrm{CaCl}_{2}$ at room temperature
As it can be seen in Fig. 10, the decrease of the permeate flux is linear during OMD. Subsequently, the final juice concentration was proportional to the initial juice concentration and the time of the dehydration process (Fig. 11). In Fig. 11, the evolution of juice concentration during the dehydration process is presented. After a long-term process $(10 \mathrm{~h})$, it can be seen that the apple juice was concentrated about $24 \%$ and beet juice about $20 \%$. Taking into consideration a small surface area of applied membranes $\left(1.20 \times 10^{-3} \mathrm{~m}^{2}\right)$, the dehydration process was very efficient. In the case of industrial scale and application membrane with a $1-\mathrm{m}^{2}$ area, the same result of dehydration will be obtained after less than $1 \mathrm{~min}$.

\section{Quality of the Juices}

The OMD processes applied for the juice concentration should not have an impact on the quality parameters of the processed juices, such as turbidity, color, antioxidant activity (TEAC equivalent), or total polyphenols (TPC) (Rózek et al. 2007; Zielinska et al. 2007; Kujawski et al. 2013).

The suitability of the OMD process for the juice concentration process was also assessed by evaluation of the juice quality parameters. For that purpose, TEAC and TPC content before and after the OMD processes were determined. The correlation between the final juice concentrations achieved during the OMD process and the TPC is presented in Table 3. It can be noticed that the TPC content increased with increasing final juice concentration, which indicates that during the OMD dehydration process, the concentrated juice did not lose polyphenol content. The antioxidant activity of the concentrated juices is also shown in Table 3. It can be seen that the OMD process does not affect the antioxidant activity as the TEAC index increased with the juice concentration, which is a very important advantage of this type of process. In the other processes utilized for beverage dehydration, like during the 
Fig. 11 The impact of duration of the process on final juice concentrations. a $0.45-\mu \mathrm{m}$ PTFE and b $0.45-\mu \mathrm{m}$ PVDF membranes (time of OMD experiment $=10 \mathrm{~h}$ )

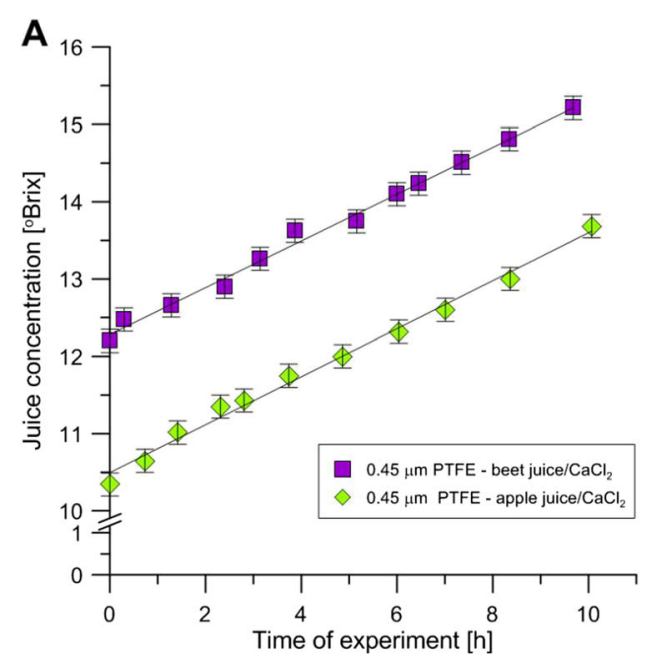

thermal technique, the diminution of TPC and antioxidant activity is often observed (Altamirano et al. 1992; Jiratanan and Liu 2004). Moreover, from the presented results, it can be concluded that beet juice is a more valuable product because of its higher antioxidant content.

\section{Conclusions}

Hydrophobic polymeric membranes were efficiently applied for juice concentration by an osmotic membrane distillation process. The factor with the strongest impact on the final juice concentration is the type of stripping solution used in the process. For this reason, higher final juice concentrations were found for experiments with $\mathrm{CaCl}_{2}$ as a stripping solution. This fact was related to the driving force of the OMD process correlated with water activity of stripping solutions $(\mathrm{NaCl}$ and $\mathrm{CaCl}_{2}$ ). Whereas, the membrane material, its pore size, and the type of juice have apparently less impact on the dehydration efficiency. However, membrane materials and their pore size have an impact on the transport properties. The higher fluxes were observed for the $0.45-\mu \mathrm{m}$ PTFE membrane.

The highest improvement of juice concentration was observed for the system apple juice $/ \mathrm{CaCl}_{2}$ and the $0.45-\mu \mathrm{m}$ PVDF membrane ( $\sim 20 \%$ higher concentration after $8 \mathrm{~h}$ of experiment). The valuable parameters of juices (total polyphenol content and antioxidant activity) were not deteriorated.

The OMD process has an impact on the physicochemical properties of polymeric membrane surfaces (e.g., contact angle, surface free energy, porosity, roughness). After the OMD process, a reduction of CA and an increase of $\mathrm{HCA}, \mathrm{SFE}$, and roughness were observed. The values of CA decrease by about $8 \%$. However, the changes of the roughness (RMS) were related to the created fouled layer of juice residue. The highest impact on the roughness was observed for $0.20-\mu \mathrm{m}$ PTFE membranes (RMS increase from $125 \pm 3$ to $150 \pm 3$ ).

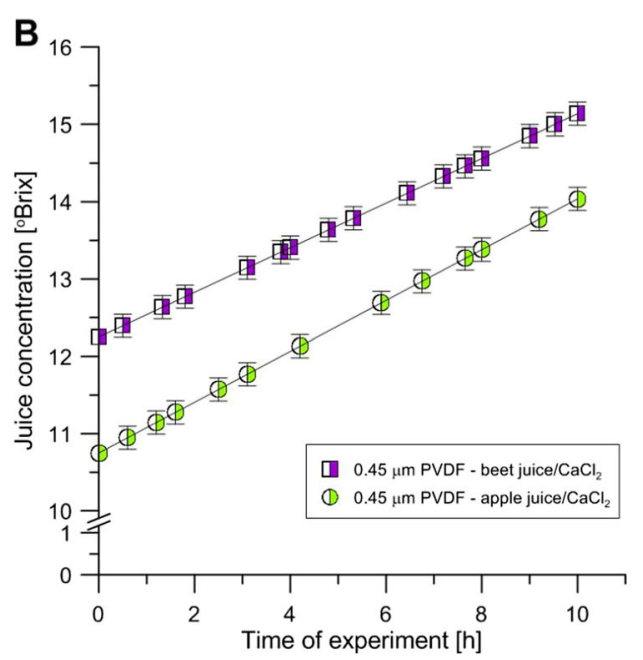

Thanks to the application of OMD, it is possible to create concentrated juices characterized by a low level of water and a high level of valuable compounds (polyphenol content and antioxidant activity). This type of process can be applied for modification and preparation of beverages classified as a functional food.

Acknowledgments This research was partially supported by statutory funds of Nicolaus Copernicus University in Torun (Faculty of Chemistry, T-109). Special thanks are due to Ms. Karolina Jarzynka for her kind assistance with the text editing.

Open Access This article is distributed under the terms of the Creative Commons Attribution 4.0 International License (http:// creativecommons.org/licenses/by/4.0/), which permits unrestricted use, distribution, and reproduction in any medium, provided you give appropriate credit to the original author(s) and the source, provide a link to the Creative Commons license, and indicate if changes were made.

\section{References}

Alloisio, M., Sottini, S., Riello, P., Giorgetti, E., Margheri, G., Cuniberti, C., \& Dellepiane, G. (2004). AFM, SEM and GIXRD studies of thin films of red polycarbazolyldiacetylenes. Surface Science, 554(1), 68-75. doi:10.1016/j.susc.2004.02.011.

Al-Sheraji, S. H., Ismail, A., Manap, M. Y., Mustafa, S., Yusof, R. M., \& Hassan, F. A. (2013). Prebiotics as functional foods: a review. Journal of Functional Foods, 5(4), 1542-1553.

Altamirano, R. C., Drdák, M., Šimon, P., Smelík, A., \& Simko, P. (1992). Stability of red beet pigment concentrate in maize starch. Journal of the Science of Food and Agriculture, 58(4), 595-596.

Alves, V. D., \& Coelhoso, I. M. (2006). Orange juice concentration by osmotic evaporation and membrane distillation: a comparative study. Journal of Food Engineering, 74(1), 125-133.

Babu, B. R., Rastogi, N. K., \& Raghavarao, K. S. M. S. (2006). Mass transfer in osmotic membrane distillation of phycocyanin colorant and sweet-lime juice. Journal of Membrane Science, 272(1-2), 5869.

Bahçeci, K. S. (2012). Effects of pretreatment and various operating parameters on permeate flux and quality during ultrafiltration of apple juice. International Journal of Food Science \& Technology, $47(2), 315-324$. 
Barbe, A. M., Bartley, J. P., Jacobs, A. L., \& Johnson, R. A. (1998). Retention of volatile organic flavour/fragrance components in the concentration of liquid foods by osmotic distillation. Journal of Membrane Science, 145(1), 67-75.

Bélafi-Bakó, K., \& Koroknai, B. (2006). Enhanced water flux in fruit juice concentration: coupled operation of osmotic evaporation and membrane distillation. Journal of Membrane Science, 269(1-2), 187-193.

Boyer, J., \& Liu, R. (2004). Apple phytochemicals and their health benefits. Nutrition Journal, 3(1), 5.

Carlsen, M., Halvorsen, B., Holte, K., Bohn, S., Dragland, S., Sampson, L., Willey, C., Senoo, H., Umezono, Y., Sanada, C., Barikmo, I., Berhe, N., Willett, W., Phillips, K., Jacobs, D., \& Blomhoff, R. (2010). The total antioxidant content of more than 3100 foods, beverages, spices, herbs and supplements used worldwide. Nutrition Journal, 9(1), 3 .

Cassano, A., Conidi, C., \& Drioli, E. (2011). Clarification and concentration of pomegranate juice (Punica granatum L.) using membrane processes. Journal of Food Engineering, 107(3-4), 366-373.

Cassano, A., Drioli, E., Galaverna, G., Marchelli, R., Di Silvestro, G., \& Cagnasso, P. (2003). Clarification and concentration of citrus and carrot juices by integrated membrane processes. Journal of Food Engineering, 57(2), 153-163.

Celere, M., \& Gostoli, C. (2004). Osmotic distillation with propylene glycol, glycerol and glycerol-salt mixtures. Journal of Membrane Science, 229(1-2), 159-170.

Chirife, J., \& Resnik, S. L. (1984). Unsaturated solutions of sodium chloride as reference sources of water activity at various temperatures. Journal of Food Science, 49(6), 1486-1488.

Claudio PR, Paulo LCL \& Cristiano PB (2009) Recent advances in fruitjuice concentration technology. In: Innovation in food engineering. Contemporary Food Engineering. $\mathrm{p}^{\wedge} \mathrm{pp}$ 161-221. CRC Press.

Courel, M., Dornier, M., Herry, J.-M., Rios, G. M., \& Reynes, M. (2000). Effect of operating conditions on water transport during the concentration of sucrose solutions by osmotic distillation. Journal of Membrane Science, 170(2), 281-289.

Daufin, G., Escudier, J. P., Carrère, H., Bérot, S., Fillaudeau, L., \& Decloux, M. (2001). Recent and emerging applications of membrane processes in the food and dairy industry. Food and Bioproducts Processing, 79(2), 89-102.

El-Abbassi A, Khayet M, Kiai H, Hafidi A \& García-Payo MC (2013) Treatment of crude olive mill wastewaters by osmotic distillation and osmotic membrane distillation. Separation and Purification Technology 104(0), 327-332.

Ghosh, R. (2002). Protein separation using membrane chromatography: opportunities and challenges. Journal of Chromatography A, 952(1-2), 13-27.

Hongvaleerat, C., Cabral, L. M. C., Dornier, M., Reynes, M., \& Ningsanond, S. (2008). Concentration of pineapple juice by osmotic evaporation. Journal of Food Engineering, 88(4), 548-552.

Hwang, K.-J., Liao, C.-Y., \& Tung, K.-L. (2008). Effect of membrane pore size on the particle fouling in membrane filtration. Desalination, 234(1-3), 16-23.

Jiao, B., Cassano, A., \& Drioli, E. (2004). Recent advances on membrane processes for the concentration of fruit juices: a review. Journal of Food Engineering, 63(3), 303-324.

Jiratanan, T., \& Liu, R. H. (2004). Antioxidant activity of processed table beets (Beta vulgaris var, conditiva) and green beans (Phaseolus vulgaris L.). Journal of Agricultural and Food Chemistry, 52(9), 2659-2670.

Kolniak-Ostek, J., Oszmiański, J., \& Wojdyło, A. (2013). Effect of 1ascorbic acid addition on quality, polyphenolic compounds and antioxidant capacity of cloudy apple juices. European Food Research and Technology, 236(5), 777-798.

Koroknai, B., Csanádi, Z., Gubicza, L., \& Bélafi-Bakó, K. (2008). Preservation of antioxidant capacity and flux enhancement in concentration of red fruit juices by membrane processes. Desalination, 228(1-3), 295-301.
Kujawa J, Rozicka A, Cerneaux S \& Kujawski W (2014) The influence of surface modification on the physicochemical properties of ceramic membranes. Colloids and Surfaces A: Physicochemical and Engineering Aspects 443(0), 567-575.

Kujawski, W., Sobolewska, A., Jarzynka, K., Güell, C., Ferrando, M., \& Warczok, J. (2013). Application of osmotic membrane distillation process in red grape juice concentration. Journal of Food Engineering, 116(4), 801-808.

Lalia BS, Guillen-Burrieza E, Arafat HA \& Hashaikeh R (2013) Fabrication and characterization of polyvinylidenefluoride-cohexafluoropropylene (PVDF-HFP) electrospun membranes for direct contact membrane distillation. Journal of Membrane Science 428(0), 104-115.

Le Marchand, L., Murphy, S. P., Hankin, J. H., Wilkens, L. R., \& Kolonel, L. N. (2000). Intake of flavonoids and lung cancer. Journal of the National Cancer Institute, 92(2), 154-160.

Li H \& Chen V (2010) Chapter 10-Membrane fouling and cleaning in food and bioprocessing. In: Cui ZF \& Muralidhara HS (eds) Membrane technology. $\mathrm{p}^{\wedge} \mathrm{pp}$ 213-254. Butterworth-Heinemann, Oxford.

Nagaraj, N., Patil, G., Babu, B. R., Hebbar, U. H., Raghavarao, K. S. M. S., \& Nene, S. (2006). Mass transfer in osmotic membrane distillation. Journal of Membrane Science, 268(1), 48-56.

Onsekizoglu, P., Savas Bahceci, K., \& Acar, J. (2010). The use of factorial design for modeling membrane distillation. Journal of Membrane Science, 349(1-2), 225-230.

Rodrigues, R. B., Menezes, H. C., Cabral, L. M. C., Dornier, M., Rios, G. M., \& Reynes, M. (2004). Evaluation of reverse osmosis and osmotic evaporation to concentrate camu-camu juice (Myrciaria dubia). Journal of Food Engineering, 63(1), 97-102.

Rózek, A., Achaerandio, I., Almajano, M. P., Güell, C., López, F., \& Ferrando, M. (2007). Solid foodstuff supplemented with phenolics from grape: antioxidant properties and correlation with phenolic profiles. Journal of Agricultural and Food Chemistry, 55(13), $5147-5155$.

Sereno, A. M., Hubinger, M. D., Comesaña, J. F., \& Correa, A. (2001). Prediction of water activity of osmotic solutions. Journal of Food Engineering, 49(2-3), 103-114.

van Reis, R., \& Zydney, A. (2007). Bioprocess membrane technology. Journal of Membrane Science, 297(1-2), 16-50.

Warczok, J., Ferrando, M., López, F., \& Güell, C. (2004). Concentration of apple and pear juices by nanofiltration at low pressures. Journal of Food Engineering, 63(1), 63-70.

Warczok, J., Ferrando, M., López, F., Pihlajamäki, A., \& Güell, C. (2007a). Reconcentration of spent solutions from osmotic dehydration using direct osmosis in two configurations. Journal of Food Engineering, 80(1), 317-326.

Warczok, J., Gierszewska, M., Kujawski, W., \& Güell, C. (2007b). Application of osmotic membrane distillation for reconcentration of sugar solutions from osmotic dehydration. Separation and Purification Technology, 57(3), 425-429.

Zambra C, Romero J, Pino L, Saavedra A \& Sanchez J (2015) Concentration of cranberry juice by osmotic distillation process. Journal of Food Engineering 144(0), 58-65.

Zhao, C. F., Li, S., Li, S. J., Song, G. H., Yu, L. J., \& Zhang, H. (2013). Extraction optimization approach to improve accessibility of functional fraction based on combination of total polyphenol, chromatographic profiling and antioxidant activity evaluation: Pyracantha fortuneana fruit as an example. Journal of Functional Foods., 5(2), 715-728.

Zielinska, D., Szawara-Nowak, D., \& Zielinski, H. (2007). Comparison of spectrophotometric and electrochemical methods for the evaluation of the antioxidant capacity of buckwheat products after hydrothermal treatment. Journal of Agricultural and Food Chemistry, 55(15), 6124-6131. 